\author{
Marquette University \\ e-Publications@Marquette
}

College of Nursing Faculty Research and

Publications

Nursing, College of

2017

\title{
Discharge Teaching, Readiness for Discharge, and Post-discharge Outcomes in Parents of Hospitalized Children
}

\author{
Marianne E. Weiss \\ Marquette University, marianne.weiss@marquette.edu \\ Kathleen Sawin \\ University of Wisconsin - Milwaukee \\ Karen Gralton \\ Children's Hospital of Wisconsin \\ Norah L. Johnson \\ Marquette University, norah.johnson@marquette.edu \\ Carol Klingbeil \\ University of Wisconsin - Milwaukee
}

See next page for additional authors

Follow this and additional works at: https://epublications.marquette.edu/nursing_fac

Part of the Nursing Commons

\section{Recommended Citation}

Weiss, Marianne E.; Sawin, Kathleen; Gralton, Karen; Johnson, Norah L.; Klingbeil, Carol; Lerret, Stacee M.; Malin, Shelly; Yakusheva, Olga; and Schiffman, Rachel, "Discharge Teaching, Readiness for Discharge, and Post-discharge Outcomes in Parents of Hospitalized Children" (2017). College of Nursing Faculty Research and Publications. 462.

https://epublications.marquette.edu/nursing_fac/462 


\section{Authors}

Marianne E. Weiss, Kathleen Sawin, Karen Gralton, Norah L. Johnson, Carol Klingbeil, Stacee M. Lerret, Shelly Malin, Olga Yakusheva, and Rachel Schiffman 


\title{
Discharge Teaching, Readiness for Discharge, and Post-discharge Outcomes in Parents of Hospitalized Children
}

\author{
Marianne E. Weiss \\ College of Nursing, Marquette University, Milwaukee, WI \\ Kathleen J. Sawin \\ College of Nursing, University of Wisconsin-Milwaukee, Milwaukee, WI \\ Children's Hospital of Wisconsin, Milwaukee, WI \\ Karen Gralton \\ College of Nursing, University of Wisconsin-Milwaukee, Milwaukee, WI \\ Children's Hospital of Wisconsin, Milwaukee, WI \\ Norah Johnson \\ College of Nursing, Marquette University, Milwaukee, WI \\ Carol Klingbeil \\ Children's Hospital of Wisconsin, Milwaukee, WI \\ Stacee Lerret \\ Children's Hospital of Wisconsin, Milwaukee, WI \\ Medical College of Wisconsin, Milwaukee, WI \\ Shelly Malin \\ Children's Hospital of Wisconsin, Milwaukee, WI \\ Olga Yakusheva \\ School of Nursing, University of Michigan, Ann Arbor, MI \\ Rachel Schiffman \\ College of Nursing, University of Wisconsin-Milwaukee, Milwaukee, WI
}

Journal of Pediatric Nursing, Vol. 34 (May-June 2017): pg. 58-64. DOI. This article is @ Elsevier (WB Saunders) and permission has been granted for this version to appear in e-Publications@Marquette. Elsevier (WB Saunders) does not grant permission for this article to be further copied/distributed or hosted elsewhere without the express permission from Elsevier (WB Saunders). 
NOT THE PUBLISHED VERSION; this is the author's final, peer-reviewed manuscript. The published version may be accessed by following the link in the citation at the bottom of the page.

\section{Abstract}

Purpose: This study explored the sequential relationships of parent perceptions of the quality of their discharge teaching and nurse and parent perceptions of discharge readiness to post-discharge outcomes (parental post-discharge coping difficulty, readmission and emergency department visits).

Design/methods: In this secondary analysis of data from a longitudinal pilot study of family selfmanagement discharge preparation, the correlational design used regression modeling with data from a convenience sample of 194 parents from two clinical units at a Midwest pediatric hospital. Data were collected on the day of discharge (Quality of Discharge Teaching Scale; Readiness for Hospital Discharge Scale), at 3 weeks post-discharge (Post-Discharge Coping Difficulty Scale), and from electronic records (readmission, ED visits).

Results: Parent-reported quality of discharge teaching delivery (the way nurses teach), but not the amount of content, was positively associated with parent perception $(B=0.54)$ and nurse assessment $(B=0.16)$ of discharge readiness. Parent-reported discharge readiness was negatively associated with post-discharge coping difficulty $(B=-0.52)$. Nurse assessment of discharge readiness was negatively associated with readmission; a one point increase in readiness (on a 10 point scale) decreased the likelihood of readmission by $52 \%$.

Conclusion: There is a sequential effect of quality of discharge teaching delivery on parent discharge readiness, which is associated with parent coping difficulty and child readmission.

Practice Implications: Efforts to improve discharge outcomes should include strategies to build nurse teaching skills for high-quality delivery of discharge teaching. In addition, routine nurse assessment of discharge readiness can be used to identify children at risk for readmission and trigger anticipatory interventions.

Keywords: Pediatric; Parent; Discharge readiness; Discharge teaching; Post-discharge; Readmission

Quality of discharge care has emerged as a priority for improving patient outcomes and reducing costs of care. While major initiatives have advanced in adult care in conjunction with reforms in payment models for hospital readmissions, the prioritization of improvement in discharge care and readmission rates is a more recent emerging concern in pediatric care (Berry et al., 2014). Approximately $6.5 \%$ of children are readmitted to the hospital within 30 days of being discharged from acute care pediatric hospitals (Berry, Toomey, et al., 2013; Berry, Ziniel, et al., 2013), with the majority of these readmissions comprised of children with complex chronic conditions, technology dependency, public insurance, and recurrent problems associated with the same organ system (Berry et al., 2011). Thirty percent of these pediatric readmissions are estimated to be preventable (Toomey et al., 2016). When parents of hospitalized children report feeling unprepared for discharge, they have difficulty transitioning from hospital to home and managing their child's complex care needs (Weiss et al., 2008; Lerret \& Weiss, 2011; Lerret et al., 2015), leading to problems that may result in returning to the hospital for an emergency department (ED) visit or readmission. In a recent study, both parents and providers consider readmissions and ED visits preventable, with parent education that prepares families for discharge and the transition to family management at home viewed as one of the major opportunities for improvement (․min et al., 2016).

Journal of Pediatric Nursing, Vol. 34 (May-June 2017): pg. 58-64. DOI. This article is @ Elsevier (WB Saunders) and permission has been granted for this version to appear in e-Publications@Marquette. Elsevier (WB Saunders) does not grant permission for this article to be further copied/distributed or hosted elsewhere without the express permission from Elsevier (WB Saunders). 
Although preparation for discharge is a multidisciplinary effort, nursing staff have primary responsibility for discharge teaching, the educational interventions to prepare the patient and family member or caregiver with the knowledge and skills needed to assume care as the patient transitions from hospital to home (Weiss et al., 2015). Discharge teaching typically consists of structured teaching about disease process and the skills needed for medical self-care. This content may not fully meet the comprehensive needs of parents for managing the demands of the child's care within their own context of home and

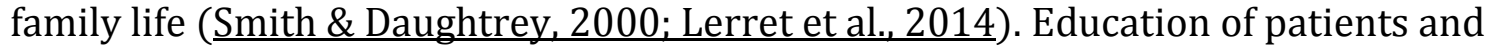
families/caregivers should encompass providing information, developing care skills, fostering informed decision-making, and building confidence in the management of care needs at home after discharge (McMurray, Johnson, Wallis, \& Patterson, 2007; Coleman et al., 2013).

Recommendations for improving discharge teaching emphasize a patient and family-centered approach in which the content and the teaching method are individualized to the patient/family characteristics and situation, rather than the typical approach of standardized information for the patients' diagnosis (Agency for Healthcare Research and Quality, n.d.-a; McBride \& Andrews, 2013). Teach-back has been widely advocated as a teaching method to improve patient/parent comprehension of discharge instructions (Agency for Healthcare Research and Quality, n.d.-b; Kornburger, Gibson, Sadowski, Maletta, \& Klingbeil, 2013). In several studies, the 'delivery' of teaching, measured as the patient's (or parent's) report of the way nurses teach, was a more significant predictor of perception of discharge readiness and subsequent difficulties encountered in coping at home after discharge (Weiss et al., 2007, 2008; Weiss \& Lokken, 2009; Weiss, Yakusheva, \& Bobay, 2011) than the amount of content taught.

What nurses do to prepare parents for hospital discharge has an impact not only at the time of hospital discharge but also extends into the post-discharge period. Developing a better understanding of the impact of discharge teaching on discharge-related outcomes for the parent and child can provide evidence to support investment of effort and resources to prepare pediatric nurses to perform high quality discharge teaching.

The aim of this study was to explore the sequential relationships of parent perceptions of the quality of their discharge teaching as well as nurse and parent perceptions of discharge readiness to post-discharge outcomes (parental post-discharge coping difficulty, readmissions and ED visits).

Journal of Pediatric Nursing, Vol. 34 (May-June 2017): pg. 58-64. DOI. This article is @ Elsevier (WB Saunders) and permission has been granted for this version to appear in e-Publications@Marquette. Elsevier (WB Saunders) does not grant permission for this article to be further copied/distributed or hosted elsewhere without the express permission from Elsevier (WB Saunders). 


\section{Theoretical Framework}

The research was guided by two theoretical frameworks: The Individual and Family Self-Management Theory (IFSMT) (yan \& Sawin, 2009) and Transitions Theory (Meleis, Sawyer, Im, Messias, \& Schumacher, 2000). The use of these theories to conceptualize the relationships investigated in the study and the measures to study these relationships is presented in the conceptual-theoretical-empirical structure in Fig. 1.

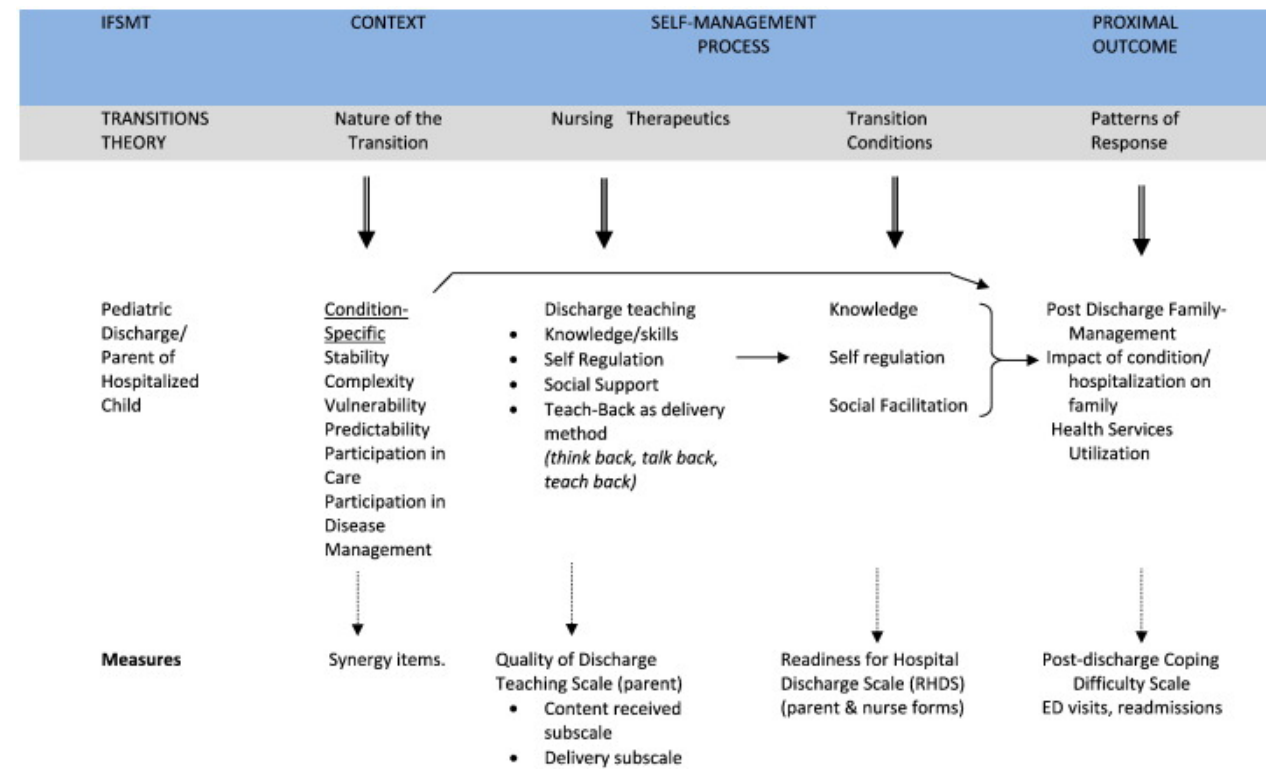

Fig. 1. Application of the individual and family self-management theory and transitions theory to the identification of study variables and measures.

The IFSMT focuses on the patient and family experience in self-management of health and illness through its key concepts of context, self-management processes, and outcomes. Following hospitalization, parents re-assume primary responsibility for managing their child's health. Transitions theory explains key elements of transitions, in this case the discharge transition from hospital to home. Considering these theories together, the self-management context and nature of the transition conceptually overlay, focusing on the characteristics of the parent, child, and clinical condition. Self-management process is patient centered; process in transitions theory is a nursing therapeutic process. For this study, the concept of nursing therapeutics was conceptualized as the discharge teaching process, which focused on the three key aspects of self-management in the IFSMT - knowledge and beliefs, self-regulation, and social facilitation - as applied to the specific preparation of parents to meet the demands of managing the child's care at home after hospital discharge. Nursing therapeutics were measured as the parent's perception of the

Journal of Pediatric Nursing, Vol. 34 (May-June 2017): pg. 58-64. DOI. This article is @ Elsevier (WB Saunders) and permission has been granted for this version to appear in e-Publications@Marquette. Elsevier (WB Saunders) does not grant permission for this article to be further copied/distributed or hosted elsewhere without the express permission from Elsevier (WB Saunders). 
quality of the process of discharge teaching. Transition conditions facilitate or inhibit the person's transitional journey. Discharge teaching sets the stage for a successful transition by readying the parent for managing the child health at home during the post-discharge period. Proximal outcomes in the IFSMT refer to self-management behaviors; the Transitions Theory concept of patterns of response refers to the parents' experiences with coping with the child's care in the post-discharge period and the difficulties they face. Readmission and ED use following hospital discharge are indicators of health status outcomes that result from difficulties in managing care needs and complications encountered in the post-discharge period.

\section{Methods}

\section{Design}

A longitudinal correlational design was used to address the study aim. This was a secondary analysis of data from a pilot study of a family self-management discharge preparation intervention. This original study compared pre-intervention baseline, $(n=90)$, intervention $(n=56)$, and concurrent control $(n=48)$ groups using a differencein-differences analysis approach (Dimick \& Ryan, 2014). There were no differences between the intervention and control groups on measures of quality of discharge teaching, readiness for discharge, post-discharge coping difficulty, or readmissions. The sample groups were therefore combined to address the aim of this current analysis. Data were collected on the day of hospital discharge, by telephone at 3 weeks post-discharge, and from electronic records abstraction through 30 days post-discharge.

\section{Subjects and Sample}

The sample for this analysis consisted of the 194 parents enrolled in the original pilot study. Parents were included if they were preparing for discharge to home following a minimum 2 day hospitalization at a pediatric academic medical center in the Midwestern United States between 2012 and 2013. The sample was a convenience sample of parents whose children were hospitalized on one of two nursing units: one unit was a 16-bed medical unit primarily for infants and children with respiratory conditions; the second unit was a 21-bed neurologic care unit. Parents were included if they could speak sufficient English to complete paper or online questionnaires. Parents and their children were excluded if discharged home to hospice care.

Journal of Pediatric Nursing, Vol. 34 (May-June 2017): pg. 58-64. DOI. This article is @ Elsevier (WB Saunders) and permission has been granted for this version to appear in e-Publications@Marquette. Elsevier (WB Saunders) does not grant permission for this article to be further copied/distributed or hosted elsewhere without the express permission from Elsevier (WB Saunders). 
NOT THE PUBLISHED VERSION; this is the author's final, peer-reviewed manuscript. The published version may be accessed by following the link in the citation at the bottom of the page.

\section{Measures}

\section{Predictor Variables}

The Quality of Discharge Teaching Scale (QDTS) measures parent perception of the quality of discharge teaching (Weiss et al., 2008). Recognizing that parents and children receive care from multiple nurses and that discharge teaching occurs throughout the hospitalization, the 18-item QDTS tool asks the parent at the end of the hospitalization to rate the quality of teaching provided by the child's nurses on two subscales, content received and quality of teaching delivery. The content received subscale focuses on the amount of discharge education content received by the parent in six domains: information about care of the child at home; knowledge about medical care treatments and medications; practice with medical care treatments and medications; knowledge about when to call the provider; expected emotions; and family learning needs of other family members. The 12-item quality of teaching delivery subscale measures parent perception of the skills of the child's nurses as educators, and includes items about listening to and answering specific questions and concerns, being sensitive to personal beliefs and values, teaching in a way that the parent can understand, providing consistent information, promoting confidence in the parent's ability to care for the child and knowing what to do in an emergency, decreasing the parent's anxiety about going home, and providing teaching at times that were good for parents and family members.

Parents rate the amount of discharge education content received and the quality of the delivery of the teaching by the child's nurses on a scale of ' 0 ' (none or not at all) to '10' (a great deal or always) with higher scores indicating higher quality of teaching. The Cronbach's alpha reliability has ranged from 0.88 to 0.92 in samples of parents of hospitalized children, adults, and older adults. (Weiss et al., 2007, 2008, 2011; Weiss \& Lokken, 2009). Construct validity was supported with exploratory principal components analysis (Weiss et al., 2007). The QDTS was completed on the day of hospital discharge, typically within $4 \mathrm{~h}$ prior to discharge. QDTS scores are reported separately for content and delivery subscales as the mean of item scores in each subscale; scores can range from 0 to 10 .

The Readiness for Hospital Discharge Scale-parent version (Parent RHDS) is a 29item tool that assesses parent perceptions of readiness for their child's discharge (Weiss et al., 2008). The RHDS is composed of five subscales: parent's personal status, child's personal status, knowledge, coping ability, and expected support. The parent answers each item on a scale from ' 0 ' (not at all) to '10' (totally) where higher scores are interpreted as

Journal of Pediatric Nursing, Vol. 34 (May-June 2017): pg. 58-64. DOI. This article is @ Elsevier (WB Saunders) and permission has been granted for this version to appear in e-Publications@Marquette. Elsevier (WB Saunders) does not grant permission for this article to be further copied/distributed or hosted elsewhere without the express permission from Elsevier (WB Saunders). 
greater readiness for hospital discharge. The total scale score was used in this study and is reported as the mean of item scores; scores can range from 0 to 10 . Cronbach's alpha reliability estimates are high ranging from 0.83 to 0.92 in various population groups including adult medical surgical patients, older adults, and parents of hospitalized children and predictive validity testing indicated an inverse relationship with post-discharge difficulty coping (Lerret \& Weiss, 2011; Lerret et al., 2015; Weiss et al., 2007, 2008, 2011; Weiss \& Lokken, 2009). Construct validity was supported from confirmatory factor analysis (Weiss \& Piacentine, 2006). The RHDS was completed on the day of hospital discharge after the completion of the QDTS.

The RN-RHDS is a parallel version of the Parent RHDS. The nurse is asked to rate the parent's readiness for their child's discharge on the same items as the parent rating. Parent and nurse ratings were collected separately without disclosure to one another. This study is the first use of the RN-RHDS with parents of hospitalized children. In prior use with adult medical - surgical patients, the nurse assessment, but not patient self-report, was inversely associated with readmission (Weiss, Yakusheva, \& Bobay, 2010; Weiss et al., 2014).

\section{Outcome Variables}

The 11-item Post-Discharge Coping Difficulty Scale (PDCDS) measures the degree of parental difficulty in coping with stress, recovery, family self- management, support, confidence, and child's adjustment after hospital discharge (Weiss et al., 2008). Parents rate the individual items on a scale of ' 0 ' (not at all) to '10' (extremely, completely or a great deal) where higher scores indicate greater difficulty. In a sample of parents of hospitalized children, the Cronbach's alpha reliability coefficient was 0.84 (Weiss et al., 2008). Construct validity was supported through factor analysis in a mixed sample of adults and parents of hospitalized children and the association of higher scores of PDCDS related to higher post-discharge utilization provided evidence in support of predictive validity in adults and children (Weiss et al., 2007, 2008). The PDCDS was completed in a telephone interview at 3 weeks post-discharge. PDCDS scores are reported as the mean of item scores in each subscale; scores can range from 0 to 10.

Utilization of post-discharge services, specifically readmission and ED visits in the first 30 days after discharge, were extracted from electronic hospital information systems. In addition, parents were asked to report occurrences of readmission and ED use since discharge during a telephone follow-up call at 3 weeks post-discharge. Because returns to the hospital for ED services or readmission could have been in the patient's home community and not to the original tertiary - level hospitalization site, utilization

Journal of Pediatric Nursing, Vol. 34 (May-June 2017): pg. 58-64. DOI. This article is @ Elsevier (WB Saunders) and permission has been granted for this version to appear in e-Publications@Marquette. Elsevier (WB Saunders) does not grant permission for this article to be further copied/distributed or hosted elsewhere without the express permission from Elsevier (WB Saunders). 
occurrences were aggregated from electronic and parent report and were recorded in dichotomous format (yes/no).

\section{Control Variables}

A parent information sheet was used on enrollment to collect the following variables to be used as control variables in the analyses: parent age, living with child's parent, education, emergency admission, and whether the child had been hospitalized previously. Age of the child, severity of illness index (associated with All Patient Refined Diagnosis Related Groups [APR-DRG], coded as minor, moderate, severe, extreme), and length of stay were extracted from electronic medical records. Context data on the complexity of care on admission was captured using a tool, which was developed for the study hospital's use based on the American Association of Critical-Care Nurses (AACN) Synergy Model for Patient Care ( $\underline{A A C N}$, n.d. $)$. The Synergy tool measures nurse assessment of the child/family's needs on 8 different domains (stability, complexity, vulnerability, resilience, predictability, participation in care, participation in decision-making and resources). Each item is scored as 1, 3, or 5 with lower scores indicating a more compromised patient requiring more complex care. Exploratory factor analysis resulted in 3 groupings of synergy factors: (a) stability/complexity; (b) vulnerability/predictability/resilience and (c) participation in care/decision making that were included in the analyses.

\section{Procedures}

Approval was obtained from the Institutional Review Board of the study hospital. Clinical nurses from two clinical units in the study hospital were recruited to participate in the study design, development of the discharge preparation intervention for the original study, and data collection. These nurses were trained in the identification of eligible parents, the consenting process, and the procedures for data collection. QDTS and RHDS data were collected via an $\mathrm{iPad}^{\mathrm{TM}}$ application. The study nurses described the study, obtained informed consent, and opened the $\mathrm{iPad}^{\mathrm{TM}}$ application. Parents then completed the tools in private and finished the application so that their nurses did not have access to the responses. Post-discharge telephone follow-up calls were completed by nurses in the Translational Research Unit of the study hospital. Data on patient characteristics and readmissions/ED visits were obtained through data searches with the assistance of information technology services at the study hospital.

Journal of Pediatric Nursing, Vol. 34 (May-June 2017): pg. 58-64. DOI. This article is @ Elsevier (WB Saunders) and permission has been granted for this version to appear in e-Publications@Marquette. Elsevier (WB Saunders) does not grant permission for this article to be further copied/distributed or hosted elsewhere without the express permission from Elsevier (WB Saunders). 


\section{Data Analysis}

Data collected from the original study were used for this analysis. Descriptive statistics were calculated for sample description and scale properties. A simultaneous equation modeling approach (Davidson \& MacKinnon, 1993) was used to account for the multiple sequential relationships of quality of discharge teaching to readiness for hospital discharge; and both quality of discharge teaching and readiness for discharge to postdischarge coping difficulty and post-discharge utilization (readmission and ED visits). Simultaneous equation regression models evaluate the impact of variables entered sequentially into the model on outcomes, while using robust standard errors to adjust for the potential bias associated with multiple equations. In the sequential analysis, an outcome variable in one equation (for example, readiness for discharge is an outcome for quality of discharge teaching) becomes a predictor variable in the subsequent equation (for post-discharge coping difficulty as an outcome), while accounting for all other variables present in the model. This approach estimates the independent contribution of each predictor to the outcome. Linear regression models were computed for all outcomes except readmission and ED visits, where logistic regression models were calculated. Control variables, comprising patient and hospitalization characteristics, were entered into all models. A fixed effect for unit was included to account for unmeasured systematic differences between units. Significance level was set at $p<0.05$.

\section{Results}

One hundred and ninety-four patients completed study measures prior to discharge and had readmission data available. The 3 week post-discharge telephone interview for collection of outcome data on the PDCDS was completed by 150 parents.

Sample characteristics are presented in Table 1 for the sample at discharge $(n=194)$ and the portion of the sample that completed the PDCDS ( $n=150)$. Parents/caregivers $(\mathrm{n}=170$ [88\%) female parent, $\mathrm{n}=18$ [9.3\%] male parent; $n=6$ [3.1\%] other, including grandparent) ranged in age from 17 to 70 , and their hospitalized children from 0 to 19. The majority of parents were non-Hispanic, White, living with the child's other parent, and had more than high school education. Two thirds of the children had an emergent admission, and a median severity of illness index of 2 (moderate), were at the mid-point of the synergy rating scales, and had a mean length of stay of 4.2 days (median 2.5).

Journal of Pediatric Nursing, Vol. 34 (May-June 2017): pg. 58-64. DOI. This article is @ Elsevier (WB Saunders) and permission has been granted for this version to appear in e-Publications@Marquette. Elsevier (WB Saunders) does not grant permission for this article to be further copied/distributed or hosted elsewhere without the express permission from Elsevier (WB Saunders). 
NOT THE PUBLISHED VERSION; this is the author's final, peer-reviewed manuscript. The published version may be accessed by following the link in the citation at the bottom of the page.

Table 1. Sample characteristics.

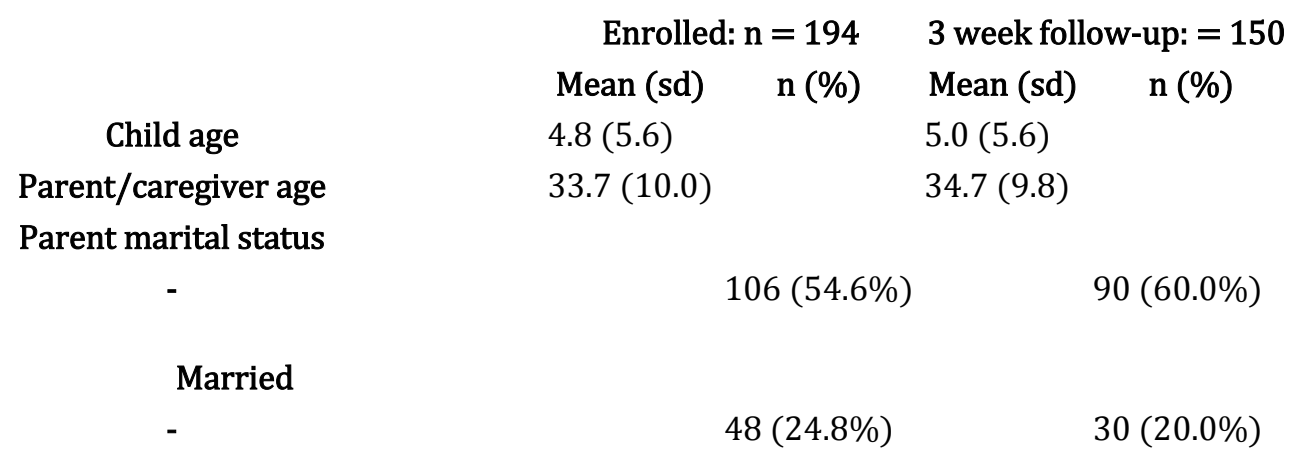

Single living with other parent

$-$

$10(5.2 \%)$

$5(3.3 \%)$

Separated

-

$37(13.9 \%) \quad 23(15.3 \%)$

Other (includes living with grandparent)

$2(1.3 \%)$

Missing

Education level - parent

$18(9.2 \%) \quad 8(5.4 \%)$

Partial high school

$-$

$46(23.7 \%) \quad 36(24.0 \%)$

High School

$53(27.3 \%) \quad 40(26.7 \%)$

Partial/junior/technical college

- $\quad 50(25.8 \%) \quad 41(27.3 \%)$

College graduate

$\begin{array}{lll}- & 24(12.4 \%) & 23(15.4 \%)\end{array}$

Graduate degree

-

$3(1.5 \%) \quad 2(15.4 \%)$

Missing

Race/ethnicity

-

$128(66.0 \%)$

$106(70.7 \%)$

White

Journal of Pediatric Nursing, Vol. 34 (May-June 2017): pg. 58-64. DOI. This article is @ Elsevier (WB Saunders) and permission has been granted for this version to appear in e-Publications@Marquette. Elsevier (WB Saunders) does not grant permission for this article to be further copied/distributed or hosted elsewhere without the express permission from Elsevier (WB Saunders). 
NOT THE PUBLISHED VERSION; this is the author's final, peer-reviewed manuscript. The published version may be accessed by following the link in the citation at the bottom of the page.

\begin{tabular}{|c|c|c|}
\hline \multicolumn{2}{|c|}{ Enrolled: $\mathrm{n}=194$} & 3 week follow-up: $=150$ \\
\hline Mean ( $\mathrm{s}$ & n (\% & Mean (sd) \\
\hline & $35(1$ & 23.(15.3\% \\
\hline
\end{tabular}

Black

$-$

$3(1.5 \%)$

$2(1.3 \%)$

Asian

$-$

Hispanic

$-$

Other

Missing

Emergent admission

-

$128(66.0 \%)$

$99(66.0 \%)$

Yes

-

$59(30.4 \%)$

$45(30.0 \%)$

No

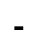

$7(3.6 \%)$

$6(4.0 \%)$.

Missing

Severity of illness

$94(48.5 \%) \quad 68(45.3 \%)$

1 minor

-

$57(29.4 \%)$

$44(29.3 \%)$

2 moderate

-

$34(17.5 \%)$

$29(19.3 \%)$

3 major

$-$

$6(3.1 \%)$

$6(4.0 \%)$

4 extreme

-

$3(1.5 \%)$

$3(2.0 \%)$

\section{Missing \\ Length of stay}


NOT THE PUBLISHED VERSION; this is the author's final, peer-reviewed manuscript. The published version may be accessed by following the link in the citation at the bottom of the page.

\begin{tabular}{|c|c|c|c|c|}
\hline & Enrollec & $=194$ & 3 week foll & -up: $=150$ \\
\hline & Mean (sd) & n (\%) & Mean (sd) & n (\%) \\
\hline Synergy & & & & \\
\hline - & $3.3(0.82)$ & & $3.3(0.84)$ & \\
\hline Stability & & & & \\
\hline - & $3.7(0.75)$ & & $3.6(0.74)$ & \\
\hline . & & & & \\
\hline 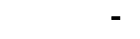 & $4.7(0.70)$ & & $5.0(0.72)$ & \\
\hline
\end{tabular}

Participation in care/decision making

Forty parents were lost to follow up. In comparison to the 150 parents who were able to be contacted for follow-up, the lost to follow-up parents were slightly younger $(p=0.01)$, single $(p=0.002)$ and had better vulnerability/predictability/resilience Synergy scores $(p=0.02)$. There were no differences on other study variables.

Table 2 shows the reliability estimates and mean scores on each of the study measures. All scales had acceptable reliability estimates above 0.70 (Tabachnick \& Fidell, 2007). Overall, parents rated that the amount of content they received about discharge was just above the middle of the scale range at 6.1 out of 10 . They rated the quality of the delivery of teaching highly with a mean score of 9.1 out of 10 . Post-discharge coping difficulty was low through the first 3 weeks at 1.7 out of 10 . Overall, the readmission rate within 30 days was 6.7\%, which is similar to the national rate of $6.5 \%$ (Berry, Toomey, et al., 2013; Berry, Ziniel, et al., 2013) and the rate of visits to the ED without readmission in the same period was $14.4 \%$.

Table 2. Scale statistics.

\begin{tabular}{|c|c|c|c|}
\hline & Cronbach's alpha & Mean (sd) & n (\%) \\
\hline QDTS delivery & 0.72 & $9.14(0.87)$ & \\
\hline QDTS received & 0.84 & $6.02(2.53)$ & \\
\hline Parent RHDS & 0.89 & $8.74(0.97)$ & \\
\hline RN-RHDS & 0.90 & $8.84(0.81)$ & \\
\hline PDCDS & 0.87 & $1.72(1.46)$ & \\
\hline visit within 30 days & & & $28(14.4 \%)$ \\
\hline nission within 30 days & & & $13(6.7 \%)$ \\
\hline
\end{tabular}

Table 3 presents the results of the regression modeling using a simultaneous equation approach to explore the sequential relationships from quality of discharge

Journal of Pediatric Nursing, Vol. 34 (May-June 2017): pg. 58-64. DOI. This article is @ Elsevier (WB Saunders) and permission has been granted for this version to appear in e-Publications@Marquette. Elsevier (WB Saunders) does not grant permission for this article to be further copied/distributed or hosted elsewhere without the express permission from Elsevier (WB Saunders). 
teaching to readiness for discharge and the care transition to post discharge coping difficulty and readmissions/ED visits. Parent perception of the quality of discharge teaching delivery was positively associated with both parent $(B=0.54)$ and nurse perception $(\mathrm{B}=0.16)$ of readiness for discharge. The amount of discharge teaching content was not significantly associated with discharge readiness. Quality of discharge teaching was not directly associated with any of the other outcomes, but was indirectly associated through its relationship to discharge readiness. Parent perception of discharge readiness (Parent RHDS), was negatively associated with post-discharge coping difficulty $(B=-0.52)$. Nurse assessment of discharge readiness (RN-RHDS) was negatively associated with readmission; a one point increase in nurse assessment of readiness (on a 10 point scale) decreased the likelihood of readmission by $52 \%$. Neither quality of discharge teaching nor readiness for discharge was associated with ED visits postdischarge. Parent RHDS and RN-RHDS were weakly correlated $(r=0.22, p=0.002)$, partially explaining their associations with different post-discharge outcomes.

Table 3. Regression models exploring the sequential relationships among study variablesa.

\begin{tabular}{|c|c|c|c|c|c|}
\hline Predictor & \multicolumn{5}{|c|}{ Outcome variables } \\
\hline Variables & RHDS & RNRHDS & PDCDS & ED & READMISSION \\
\hline QDTS - delivery & $\begin{array}{l}0.541 \\
(p<0.001)\end{array}$ & $\begin{array}{l}0.160 \\
(p=0.027)\end{array}$ & & & \\
\hline QDTS - received & & & & & \\
\hline Parent RHDS & & & $\begin{array}{l}-0.518 \\
(p=0.002)\end{array}$ & & \\
\hline RNRHDS & & & & & $\begin{array}{l}0.482 \\
(p=0.043)\end{array}$ \\
\hline Child's age & & & & $\begin{array}{l}0.717 \\
(p=0.045)\end{array}$ & \\
\hline ducation $=$ college graduate & & & $\begin{array}{l}0.647 \\
(p=0.029)\end{array}$ & & \\
\hline Race $=$ white & & $\begin{array}{l}0.437 \\
(p=0.005)\end{array}$ & & & \\
\hline Length of stay & & $\begin{array}{l}-0.0341 \\
(p<0.001)\end{array}$ & & & \\
\hline $\begin{array}{l}\text { Synergy score } \\
\text { lity/predictability/resilience) }\end{array}$ & & & & & $\begin{array}{l}4.530 \\
(p=0.009)\end{array}$ \\
\hline
\end{tabular}

(vulnerability/predictability/resilience)

QDTS: Quality of Discharge Teaching Scale; RHDS: Readiness for Hospital Discharge Scale. PDCDS: Post-Discharge Coping Difficulty Scale; ED: emergency department visit. aRelationships significant at $p<0.05$ are reported. All regression equations contain the following variables which were not-significantly associated with the outcomes: Parent age, parents living together, emergent admission, APR-DRG severity and mortality risk indices, synergy mean scores for stability/complexity and for participation in care/decision-making, unit-level fixed effect.

Journal of Pediatric Nursing, Vol. 34 (May-June 2017): pg. 58-64. DOI. This article is @ Elsevier (WB Saunders) and permission has been granted for this version to appear in e-Publications@Marquette. Elsevier (WB Saunders) does not grant permission for this article to be further copied/distributed or hosted elsewhere without the express permission from Elsevier (WB Saunders). 
Patient characteristics associated with the outcome measures are also evident in Table 3. White race and shorter length of stay were associated with high nurse assessment scores on readiness for discharge, parents who were college graduates experienced greater post-discharge coping difficulty, child age was inversely associated with ED use postdischarge ( $\mathrm{OR}=0.71)$, and a higher admission synergy score (indicating minimal vulnerability/ high predictability/high resilience) were associated with greater likelihood of readmission.

\section{Discussion}

The results of this study point to the trajectory of influence of quality of discharge teaching to parental readiness for discharge and subsequent post-discharge coping difficulty and readmissions. While in general, quality of discharge teaching is rated highly, most parents are ready for discharge and have little difficulty coping after discharge, the results indicate that when quality of discharge teaching delivery is low, the cascade of effects leads to negative outcomes for parents and their children.

The findings on the trajectory of influence from parent perception of the quality of delivery of the discharge teaching to parent readiness for discharge and post-discharge coping difficulty mirrors findings from prior studies by the authors with general pediatric (Weiss et al., 2008), and solid organ transplant parents (Lerret \& Weiss, 2011; Lerret et al., 2015). The strength of the association of QDTS- delivery to Parent RHDS, with a 1 point change (on a 10 point scale) in quality of delivery of discharge teaching associated with a half point ( 0.54 ) change (on a 10 point scale) in discharge readiness, underscores the importance of the skills nurses use to teach parents. While content is certainly important, in the absence of high quality teaching skills, the teaching becomes less effective in preparing parents for discharge.

Parent perception of readiness to take their child home from the hospital is an important indicator of potential difficulties they will experience when at home. Parental perceived lack of or low readiness sets the stage for a difficult transition to home and parental difficulties in managing their home care situation. Low Parent RHDS scores should serve as a risk indicator and trigger for anticipatory interventions to reduce the difficulties parents may encounter and increase their ability and confidence to cope with the problems they encounter.

Nurse assessments of discharge readiness were less strongly associated with the quality of discharge teaching but were predictive of readmissions. An increase of one point

Journal of Pediatric Nursing, Vol. 34 (May-June 2017): pg. 58-64. DOI. This article is @ Elsevier (WB Saunders) and permission has been granted for this version to appear in e-Publications@Marquette. Elsevier (WB Saunders) does not grant permission for this article to be further copied/distributed or hosted elsewhere without the express permission from Elsevier (WB Saunders). 
on the RN-RHDS was independently associated with a $>50 \%$ lower likelihood of readmission. It is of interest that Parent RHDS and RN-RHDS were associated with different outcomes; parent ratings with how well they coped with problems post-discharge and nurse assessments anticipating the clinically significant problems that result in readmission. Nurses' and parents' assessments of readiness for discharge were only weakly associated and may reflect different priorities. Parents' views of readiness may be shaped by the home realities and nurses' assessments by their clinical knowledge, judgment, and experiences with similar patients.

As expected, several patient characteristics were associated with the outcome measures. Most are in the expected direction. The relationship of a higher synergy score to increased risk of readmission is perplexing. The patients whom the nurses assessed at admission as being less vulnerable, more resilient and more predictable actually had higher readmission rates. Synergy scores can change over the course of hospitalization; the admission score may not have been the most useful for predicting outcomes. Another explanation may be that the high predictability/high resilience families were those who had longstanding experience with chronic illness and multiple admissions, making them 'experienced' with the illness, their child, and care management, but with high risk of readmission due to disease progression. It is also possible that the amount and content of discharge teaching may have been more limited if parent needs were minimized when Synergy scores were already high. It will be important to disentangle this finding in future studies.

\section{Limitations}

This study is a secondary analysis of a pilot intervention study. In combining the sample of intervention and control parents, a limitation of this analysis is that the intervention parents had different discharge preparation experiences than the control group parents. While not producing significant differences in the outcomes measured, the differences in discharge preparation may have nonetheless affected the relationships among the variables in this secondary analysis. The study is also limited by its sample size for the number of variables studied and the use of a convenience sample within a single pediatric medical center. It will be important in the future to replicate with other more diverse samples. Given the current focus nationally on discharge preparation, the findings should be viewed within the context of the inter-professional nature of discharge care. Although nurses contribute to the discharge outcomes studied here, other health team member contributions are unmeasured. The readmission rate in this study is comparable to the national rate for pediatric readmissions, but full capture of data on readmissions is

Journal of Pediatric Nursing, Vol. 34 (May-June 2017): pg. 58-64. DOI. This article is (C Elsevier (WB Saunders) and permission has been granted for this version to appear in e-Publications@Marquette. Elsevier (WB Saunders) does not grant permission for this article to be further copied/distributed or hosted elsewhere without the express permission from Elsevier (WB Saunders). 
difficult. In this study, we combined reports by parents with information from the hospital's electronic record in an attempt to capture out-of-facility returns to the hospital, although the accuracy cannot be definitively assessed. The Synergy score was a measure completed by clinical nurses at the study site as part of the routine admission assessment and therefore subject to measurement error and lack of inter-rater reliability. The Synergy needs tool was originally developed to be paired with a nurse competency tool to facilitate matching the needs of the patient/family to the competency of the nurse. Thus, it may not be appropriate for the way it was employed in this study.

The IFSMT and Transitions Theory were useful frameworks for guiding the selection of measures for the study. While the measures selected addressed key components of the theories, including parent knowledge, self-management skills and abilities, and perceptions of availability of social support, they were not specifically developed as empirical measures of the theory concepts. Future development of instruments to more directly measure the concepts of these theories will contribute to greater understanding of the relevance of these theories to discharge transition research.

\section{Implications for Practice}

Investment in assuring that discharge teaching is of high quality and parents are ready for discharge is a proactive strategy for improving patient/family and health system outcomes. How well nurses teach parents has an impact on parent perception of readiness for discharge, a factor in patient satisfaction ratings (Centers for Medicare and Medicaid Services, n.d.), and their readiness for managing their child's care at home. How ready the parent is for discharge from the nurse's perspective is associated with whether the child returns for readmission, at high cost to the parent and health system.

Implementing parent evaluation of discharge teaching and parent and nurse assessments of discharge readiness as standard practices are important steps in early identification of families at risk for poor post-discharge outcomes. Formalizing these assessments before discharge can trigger anticipatory services to support the family during the transition to care at home.

There are impediments to high quality discharge teaching that need to be addressed. Discharge teaching has been identified as a frequent area of missed or deficient nursing care (Kalisch \& Williams, 2009). Heavy nurse work-loads and prioritization of care for more acute patients cause time constraints that lead to rapid-fire telling of instructions as the family is about to leave the hospital rather than skilled, high quality interactive and

Journal of Pediatric Nursing, Vol. 34 (May-June 2017): pg. 58-64. DOI. This article is @ Elsevier (WB Saunders) and permission has been granted for this version to appear in e-Publications@Marquette. Elsevier (WB Saunders) does not grant permission for this article to be further copied/distributed or hosted elsewhere without the express permission from Elsevier (WB Saunders). 
patient/family focused discharge teaching. It has been documented that better nurse staffing levels in the form of smaller nurse-to-patient ratios and higher hours-per-patient day are associated with better quality of discharge teaching and fewer readmissions (Tubbs-Cooley, Cimiotti, Silber, Sloane, \& Aiken, 2013; Weiss et al., 2011). Assuring adequate staffing to allow time for high-quality teaching will align with organizational goals for improving parent experience of care and reducing readmissions.

Teaching nurses how to improve the quality of their teaching is an important upstream approach to addressing the problem of inadequate discharge preparation. Preparing nurses for discharge teaching in pre-licensure education, hospital orientation, staff development, and preceptoring programs is essential to develop skillful and effective delivery of discharge education; yet this preparation often focuses on what content to teach for patients with specific medical conditions, rather than how to teach. Teach-back is one method currently being taught to health care professionals but other methods should also be incorporated as schools of nursing and staff development educators place emphasis on the "how-to" of patient education. Including preparation in discharge teaching in staff orientation and unit-based education initiatives are important strategies to consider. However, education alone may not improve the quality of teaching. Leadership support to monitor discharge teaching performance, modify clinical care delivery systems as needed, and evaluate staffing patterns are critical to solving this important yet often overlooked aspect of care. Emphasis on improving the quality of teaching before discharge will support the hospital's and nursing's strategic efforts to improve discharge care and outcomes.

\section{Conclusions}

There is a sequential cascade of effects that starts with the quality of discharge teaching delivery by the child's nurses on parent-reported discharge readiness, which is then associated with parent coping difficulty. Nurse assessment of discharge readiness, weakly but significantly associated with the quality of discharge teaching delivery, is a predictor of the likelihood of the child's readmission.

\section{Funding}

This work was supported by the Pediatric Nursing Research Consortium, a joint project of Children's Hospital of Wisconsin, University of Wisconsin Milwaukee College of Nursing, and Marquette University College of Nursing. Additional funds were provided by the Sophie Schroeder Endowed Chair for Nursing, held by Nancy Korom, Chief Nursing Officer and Vice President - Children's Hospital of Wisconsin

Journal of Pediatric Nursing, Vol. 34 (May-June 2017): pg. 58-64. DOI. This article is (C Elsevier (WB Saunders) and permission has been granted for this version to appear in e-Publications@Marquette. Elsevier (WB Saunders) does not grant permission for this article to be further copied/distributed or hosted elsewhere without the express permission from Elsevier (WB Saunders). 
NOT THE PUBLISHED VERSION; this is the author's final, peer-reviewed manuscript. The published version may be accessed by following the link in the citation at the bottom of the page.

\section{Acknowledgments}

We would like to acknowledge the following for their contribution and support: study nurses, Jamie Thompson, Stacy Zodrow, Megan (Kroll) Ming, Elisa Gricunas, Holly Orlowski, Katie Junemann, Mary Biskupski, Maggie Fredericks, Amanda Mercado, Michelle Miklosh, Michelle Donlin, Jodi Neuwirth, Stephanie Essma, Molly Kaul, Cheryl Kornburger; Data entry staff Areyl Goff; Nurse Leaders on the study units: Eileen Sherburne, Kimberly Zimmanck, Amanda Quesnell, Stacy Zodrow; Data collection: the staff in the Transitional Research Unit ; operational support: Chief Nursing Officer Nancy Korom.

\section{References}

Agency for Healthcare Research and Quality, n.d Agency for Healthcare Research and Quality (n.d.-a). Care transitions from hospital to home:IDEAL discharge planning process. http://www.ahrq.gov/professionals/systems/hospital/engagingfamilies/strategy4/index.html.

Agency for Healthcare Research and Quality, n.d Agency for Healthcare Research and Quality (n.d.-b). Health literacy universal precautionstoolkit, 2nd ed.: Use the Teach-Back method. http://www.ahrq.gov/professionals/quality-patient-safety/quality-resources/tools/literacytoolkit/healthlittoolkit2-tool5.html.

American Association of Critical-Care Nurses, n.d American Association of Critical-Care Nurses (n.d.). Synergy model for patient care.

http://www.aacn.org/wd/certifications/content/synmodel.pcms?menu=certification.

Amin et al., 2016 D. Amin, R. Ford, S.R. Ghazarian, B. Love, T.L. Cheng Parent and physician perceptions regarding preventability of pediatric readmissions Hospital Pediatrics, 6 (2) (2016), pp. 80-87

Berry et al., 2013 J.G. Berry, S.L. Toomey, A.M. Zaslavsky, A.K. Jha, M.M. Nakamura, D.J. Klein, ..., M.A. Schuster Pediatric readmission prevalence and variability across hospitals JAMA, 309 (4) (2013), pp. $372-380$

Berry et al., 2013 J.G. Berry, S.I. Ziniel, L. Freeman, W. Kaplan, R. Antonelli, J. Gay, ..., D. Goldmann Hospital readmission and parent perceptions of their child's hospital discharge International Journal for Quality in Health Care, 25 (5) (2013), pp. 573-581, 10.1093/intqhc/mzt051]

Berry et al., 2014 J.G. Berry, K. Blaine, J. Rogers, S. McBride, E. Schor, J. Birmingham, ..., C. Feudtner A framework for pediatric hospital discharge care informed by legislation, research, and practice JAMA Pediatrics, 186 (10) (2014), pp. 955-962

Berry et al., 2011 J.G. Berry, D.E. Hall, D.Z. Kuo, E. Cohen, R. Agrawal, C. Feudtner, ..., J. Neff Hospital utilization and characteristics of patients experiencing recurrent readmissions within children's hospitals JAMA, 305 (7) (2011), pp. 682-690

Centers for Medicare and Medicaid Services, n.d Centers for Medicare \& Medicaid Services (n.d.). Hospital consumer assessment ofhealthcare providers and systems.

http://www.hcahpsonline.org.

Coleman et al., 2013 E.A. Coleman, A. Chugh, M.V. Williams, J. Grigsby, J.J. Glasheen, M. McKenzie, S.-J. Min Understanding and execution of discharge instructions American Journal of Medical Quality, 28

(5) (2013), pp. 383-391

Journal of Pediatric Nursing, Vol. 34 (May-June 2017): pg. 58-64. DOI. This article is @ Elsevier (WB Saunders) and permission has been granted for this version to appear in e-Publications@Marquette. Elsevier (WB Saunders) does not grant permission for this article to be further copied/distributed or hosted elsewhere without the express permission from Elsevier (WB Saunders). 
NOT THE PUBLISHED VERSION; this is the author's final, peer-reviewed manuscript. The published version may be accessed by following the link in the citation at the bottom of the page.

Davidson and MacKinnon, 1993 R. Davidson, J.G. MacKinnon Estimation and inference in econometrics Oxford University Press, New York, USA (1993)

Dimick and Ryan, 2014 J.B. Dimick, A.M. Ryan Methods for evaluating changes in health care policy: The difference-in-differences approach JAMA, 312 (22) (2014), pp. 2401-2402

Kalisch and Williams, 2009 B. Kalisch, R. Williams Development and psychometric testing of a tool to measure missed nursing care (MISSCARE Survey) Journal of Nursing Administration, 39 (5) (2009), pp. 211-219

Kornburger et al., 2013 C. Kornburger, C. Gibson, S. Sadowski, K. Maletta, C. Klingbeil Using "teach-back" to promote a safe transition from hospital to home: An evidence-based approach to improving the discharge process Journal of Pediatric Nursing, 28 (3) (2013), pp. 282-291

Lerret and Weiss, 2011 S. Lerret, M.E. Weiss How ready are they? Parents of pediatric solid organ transplant recipients and the transition from hospital to home following transplant Pediatric Transplantation, 15 (6) (2011), pp. 606-616

Lerret et al., 2015 S.M. Lerret, M.E. Weiss, G. Stendahl, S. Chapman, J. Menendez, L. Williams, ..., P. Simpson Pediatric solid organ transplant recipients: Transition to home and chronic illness care Pediatric Transplantation, 19 (1) (2015), pp. 118-129

Lerret et al., 2014 S.M. Lerret, M.E. Weiss, G. Stendahl, S. Chapman, K. Neighbors, K. Amsden, ..., E.M. Alonso Transition from hospital to home following pediatric solid organ transplant: Qualitative findings of parent experience Pediatric Transplantation, 18 (2014), pp. 527-537

McBride and Andrews, 2013 M. McBride, G.J. Andrews The transition from acute care to home: A review of issues in discharge teaching and a framework for better practice Canadian Journal of Cardiovascular Nursing, 23 (3) (2013), pp. 18-24

McMurray et al., 2007 A. McMurray, P. Johnson, M. Wallis, E. Patterson General surgical patients' perspectives of the adequacy and appropriateness of discharge planning to facilitate health decision-making at home Journal of Clinical Nursing, 16 (9) (2007), pp. 1602-1609

Meleis et al., 2000 A.I. Meleis, L.M. Sawyer, E.-O. Im, D.K.H. Messias, K. Schumacher Experiencing transitions: An emerging middle-range theory Advances in Nursing Science, 23 (1) (2000), pp. $12-28$

Ryan and Sawin, 2009 P. Ryan, K.J. Sawin The individual and family self-management theory: Background and perspectives on context, process, and outcomes Nursing Outlook, 57 (4) (2009), pp. 217-225

Smith and Daughtrey, 2000 L. Smith, H. Daughtrey Weaving the seamless web of care: An analysis of parents' perceptions of their needs following discharge of their child from hospital Journal of Advanced Nursing, 31 (4) (2000), pp. 812-820

Tabachnick and Fidell, 2007 B. Tabachnick, L.S. Fidell Using multivariate statistics (5 ed.), Pearson Education, Inc., Boston, MA (2007)

Toomey et al., 2016 S.L. Toomey, A. Peltz, S. Loren, M. Tracy, K. Williams, L. Pendgeroth, A. Ste Marie, ..., M.A. Schuster Potentially preventable 30-day hospital readmissions Pediatrics, 138 (2) (2016), p. e20154182

Tubbs-Cooley et al., 2013 H.L. Tubbs-Cooley, J.P. Cimiotti, J.H. Silber, D.M. Sloane, L.H. Aiken An observational study of nurse staffing levels and readmission among children hospitalized for common conditions BMJ Quality \& Safety, 22 (9) (2013), pp. 735-742

Weiss and Lokken, 2009 M.E. Weiss, L. Lokken Predictors and outcomes of postpartum mothers' perceptions of readiness for discharge after birth JOGNN, 38 (4) (2009), pp. 406-417

Journal of Pediatric Nursing, Vol. 34 (May-June 2017): pg. 58-64. DOI. This article is @ Elsevier (WB Saunders) and permission has been granted for this version to appear in e-Publications@Marquette. Elsevier (WB Saunders) does not grant permission for this article to be further copied/distributed or hosted elsewhere without the express permission from Elsevier (WB Saunders). 
NOT THE PUBLISHED VERSION; this is the author's final, peer-reviewed manuscript. The published version may be accessed by following the link in the citation at the bottom of the page.

Weiss and Piacentine, 2006 M.E. Weiss, L.B. Piacentine Psychometric properties of the readiness for hospital discharge scale Journal of Nursing Measurement, 14 (3) (2006), pp. 163-180

Weiss et al., 2015 M.E. Weiss, K.L. Bobay, S. Bahr, L. Costa, R. Hughes, D.E. Holland Discharge preparation: A model for hospital discharge transition care Journal of Nursing Administration, 45 (12) (2015), pp. 606-614

Weiss et al., 2014 M.E. Weiss, L. Costa, O. Yakusheva, K. Bobay Validation of patient and nurse short forms of the readiness for hospital discharge scale and their relationship to return to the hospital Health Services Research, 49 (1) (2014), pp. 304-317

Weiss et al., 2008 M. Weiss, N. Johnson, S. Malin, T. Jerofke, C. Lang, E. Sherburne Readiness for discharge in parents of hospitalized children Journal of Pediatric Nursing, 23 (4) (2008), pp. 282-295

Weiss et al., 2007 M.E. Weiss, L.B. Piacentine, L. Lokken, J. Ancona, J. Archer, S. Gresser, ..., T. VegaStromberg Perceived readiness for hospital discharge in adult medical-surgical patients Clinical Nurse Specialist, 21 (1) (2007), pp. 31-42

Weiss et al., 2010 M.E. Weiss, O. Yakusheva, K.L. Bobay Nurse and patient perceptions of discharge readiness in relation to post-discharge utilization Medical Care, 48 (5) (2010), pp. 482-486

Weiss et al., 2011 M. Weiss, O. Yakusheva, K. Bobay Quality and cost analysis of nurse staffing, discharge preparation, and post-discharge utilization Health Services Research, 46 (5) (2011), pp. 14731494

${ }^{1}$ Currently at the College of Nursing-University of Wisconsin Milwaukee, United States. 2Currently at Mennonite College of Nursing, Illinois State University, United States.

Journal of Pediatric Nursing, Vol. 34 (May-June 2017): pg. 58-64. DOI. This article is @ Elsevier (WB Saunders) and permission has been granted for this version to appear in e-Publications@Marquette. Elsevier (WB Saunders) does not grant permission for this article to be further copied/distributed or hosted elsewhere without the express permission from Elsevier (WB Saunders). 